\title{
Social Sustainability; Maintenance of Socio-Cultural Characteristics: A Case Study of El-Raml Station
}

\author{
By Bakr Gomaa ${ }^{1}$, Nadine Sakr ${ }^{1}$
}

\begin{abstract}
Social sustainability refers to "development that leads to the harmonious evolution of society". This paper explores the concept of social sustainability and the aspects it encompasses, with particular focus on the maintenance of socio-cultural characteristics deemed important by people. The research investigates the socio-cultural aspects in the case study area of El-Raml Station, the old city centre of Alexandria, Egyptt, which is known for its historical value. The development of the area poses a number of threats, including the loss of its character. The case study examines these threats, setting a number of testable criteria to help evaluate and maintain preferred socio-cultural characteristics, and thus advance social sustainability. The used methods comprise literature review, interviews and a questionnaire. The research concludes with a number of findings that are expected to clarify the maintenance of socio-cultural characteristics in El-Raml Station. The area is found to have a strong sense of place, and is perceived by its visitors as an important shopping area. On the other hand, it suffers from social polarisation and compromised feelings of safety.
\end{abstract}

Keywords: social sustainability, socio-cultural characteristics, Alexandria, El Raml Station, cultural character

\section{Introduction}

The pillars of sustainability have been identified and verified to include three factors. Set research in the recent past has focused on the economic and environmental dimensions, overlooking the critical social dimension. The negligence of the input of social development in research has led to its implications being vague and under-theorized. "Social sustainability is a concept in chaos, and we argue that this severely compromises its importance and utility" (Vallance, 2011). Researchers believe that there are still uncertainties in definition, criteria and measurement systems regarding the social component of sustainable development, (Landorf, 2011). Bacon (2012) states that social sustainability lacks a clear definition in policy discourse or practice. This paper aims to define social sustainability and clarify its different aspects, focusing in particular on preserving sociocultural preferences. It is hoped that this research will unravel the way people perceive changes occurring to their experience in El-Raml Station, Alexandria, an area of powerful character and historical value that has witnessed noticeable changes over the years. A framework of criteria is then constructed to assess this issue in the area.

\section{Research Methodology}

Literature investigation is part of the research methodology; the review covers a number of references to obtain qualitative data and insights on the numerous aspects of social sustainability mentioned by several theorists. A framework of distinct aspects regarding the maintenance of socio-cultural characteristics is then concluded and used as the base for the remaining parts of the research: namely the case study assessment; which comprises a questionnaire and scheduled interviews. 
The case study of El-Raml Station is chosen due to its strong impact on the people of Alexandria. It is difficult to find an Alexandrian that does not have memories associated with this place. The questionnaire aims to acquire quantitative results, assessing the maintenance of socio-cultural characteristics in El-Raml Station, including how different social and economic groups perceive them. Scheduled interviews strengthen validity by providing a more intimate insight.

\section{Exploring Social Sustainability}

The definitions of social sustainability and the scope it encompasses have been widely debated among planners and theorists. Polese and Stren (2000) regard social sustainability as development or growth that leads to the harmonious evolution of society, creating an environment that is well suited for the cohabitation of socially diverse groups, whilst promoting social cohesion and a better quality of life for the general population. Holden (2012) gives a similar definition stating that social sustainability is " a process of urban development, supported by policies and institutions that ensure harmonious social relations, enhance social integration and improve living conditions for all groups".

Other scholars give a more in-depth analysis, identifying several aspects of social sustainability. Sachs (1999) recognizes a number of constituent elements such as social homogeneity, employment, equitable incomes and access to goods and services. He also highlights the importance of "political sustainability" concerning democracy and human rights and "cultural sustainability" regarding the balance between external imposed change and continuity. Godschalk (2004) approaches the concept quite differently; he added a social sustainability "livability" component to Campbell's (1996) urban planning tripartite conflicts of: 'resource', 'development' and 'property', highlighting the ways in which concerns of urban planning such as economic growth can hinder the search for livable cities. Vallance, et al (2011) argue that this approach is significant as it exposes potential conflicts rather than assuming that sustainable development will result in advantageous outcomes for all parties.

Chiu (2003) evaluates social sustainability in an urban context in Hong Kong; she identifies three aspects relating to it. The first aspect is concerned with the social limits and constraints of development- stating that how socially sustainable a particular design decision is depends on specific social relations, values, customs and structure. The second 'environment-oriented' aspect relates to ecological limits and refers to the social prerequisites necessary in order to achieve environmental sustainability. The third 'people-oriented' aspect refers to improving people's wellbeing and ensuring the equitable distribution of resources whilst increasing social cohesion.

It could then be deduced that social sustainability is the harmonious growth of a diverse society; which comprises numerous attributes such as access to basic needs, environmental ethics, sociocultural maintenance, as well as a just political system.

The critical question here is how can social sustainability be assessed? El-Husseiny and Kesseiba (2012) stated five main doctrines for assessing the social sustainability of communities. The first aspect is 'social capital, referring to shared interests, participation in community activities, common experiences and social bonds. The second aspect is the 'environment', entailing the maintenance of a safe and healthy environment as well as the protection of human health and quality of life. Another vital aspect is the 'economy', generally concerning meeting local needs, employment, and creating a vibrant economy. The fourth one is 'policy', regarding democracy and participatory decision-making. The final aspect is 'place making', addressing public space design criteria and sense of place.

Vallance, et al (2011) develop a tripartite of social sustainability aspects, as shown in Figure 1. "Development Social Sustainability" addresses basic tangible needs such as potable water and healthy food, as well as less tangible needs concerning employment, education and equity. 


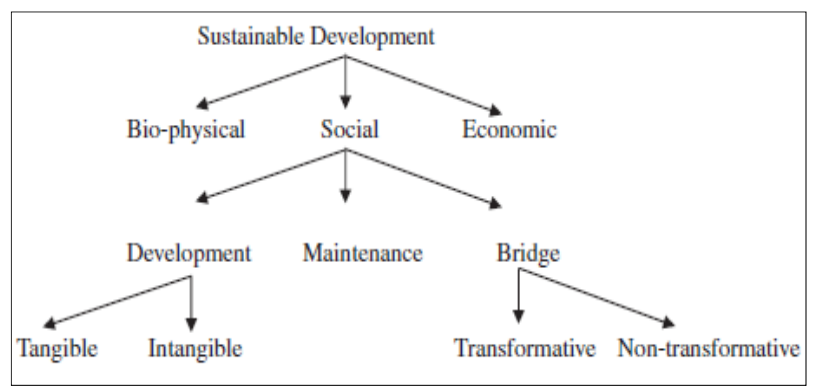

Figure 1: Three strands of social sustainability. (Source: Vallance, 2011)

This brings about an important issue regarding how people accept suggested changes. "Bridge Social Sustainability" is another term used in (Vallance, 2011) and it is concerned with altering people's behaviour and ethics in order to achieve bio-physical environmental goals. Various fields are involved; psychology, socio-ecological studies, environmental sociology and human geography. According to Foladori (2005), the aim is to build better 'bridges' between people and the bio-physical environment. 'Bridge Social Sustainability' is classified into two categories: 'Nontransformative' schemes and 'transformative' schemes. 'Non-transformative' schemes involve the adoption of technological advances such as the installation of recycling systems and solar panels to encourage people to slightly alter their familiar ways of doing things, yet without requiring a fundamental change in their lifestyle. However, 'transformative' schemes entail a fundamental change in people's lifestyles or beliefs. These often face resistance and are more difficult to apply, such as the use of composting toilets.

Another equally important aspect of social sustainability is its maintenance. 'Maintenance Social Sustainability' refers to the "traditions, practices, preferences and places people would like to see maintained" (Vallance, 2011). It therefore involves social, cultural and environmental factors that underpin people's quality of life and preferences, such as social networks, leisure opportunities and pleasant work spaces.

\section{Maintenance of Socio-Cultural Characteristics}

This paper builds on the work of Vallance (2011), and continues to study their definition of 'maintenance social sustainability'. In Vallance's work, the authors give a rather broad description of the term, for example: "Maintenance social sustainability is, therefore, concerned with the ways in which social and cultural preferences and characteristics, and the environment, are maintained over time". This research gives a precise classification of interrelated aspects for a clearer understanding of the term.

The maintenance of socio-cultural characteristics is an aspect of social sustainability that refers to the preservation of people's preferred lifestyles. It is important to note that a number of sociocultural characteristics are affected by other aspects of social sustainability, such as public space design criteria. For example; it is not possible to have a safe environment if the streets are poorly laid out or present hazards to pedestrians. The convenience of an environment to its occupants will most likely be compromised if services and facilities and placed inappropriately far away from dwellings, or if insufficient public transportation is available. Social cohesion will be adversely affected if community space is limited or of poor quality.

This association between space design and social sustainability is not studied here due to time and financial constraints. They, however, must be discussed in future research to provide a more complete picture of the topic.

It is concluded that the maintenance of socio-cultural characteristics can be attributed to four main aspects: enhancement of social cohesion, preservation of cultural character and sense of place, provision of a safe environment and sustenance of preferred convenient practices. 


\subsection{Social Cohesion}

According to Berkman et al, (2000), social cohesion refers to two broad intertwined features of society; firstly 'the absence of latent social conflict', whether in the form of racial discrimination, inequitable incomes or other forms of polarisation. This equips the community for peaceful co-habilitation, while allowing a diverse social and economic society. Secondly; 'the presence of strong social bonds' measured by social capital. Putnam (1993) defines social capital in terms of features of social organization such as social networks, norms and trust that facilitate cooperation for mutual benefit.

\subsection{Sense of Place/Cultural Character}

"To be inside a place is to belong to it and to identify with it" (Relph, 1976). This relates to the physical environment as well as the people who occupy it. Talen (1999) mentions that pride/sense of place is closely related to the built of environment, as those feelings are said to be influenced by the perceived quality of a place.

Pride and sense of attachment to a place are also bound to the concepts of belonging and territoriality. People will have a sense of pride and identity if they participate in the community with other members and contribute to the area's continuous development. This will enhance the sense of community and create vested interest.

Knox (2011) states that a place is always socially-constructed and that a crucial element in the social construction of a place is the ability of people to define themselves in relation to the material world. People constantly generate perceptions about buildings and spaces through routine behaviours and practices. This leads to certain images and emotions being evoked as a result of the experiences and memories associated with a particular place (El-Husseinya et al, 2012).

One can not overlook Lynch's (1960) construal mentioning that the coherence of a mental image of a particular place may gain identity due to 'long familiarity'. Therefore, preserving an area's desirable cultural identity and character is vital, and ensures evoking positive emotions and a sense of place and belonging. This does not denote that changes/developments that occur over time are detrimental; it merely indicates that future developments or alterations should ensure the maintenance of an area's desirable cultural character.

\subsection{Safety}

The perceived safety of a community is found to be a fundamental aspect of social sustainability (Barton, 2000). Maslow (1954), in his pyramid of needs; locates 'Safety and Security' directly above the base level that holds 'people's physiological needs'. Safety is essential if any form of social activity is to take place. If people feel unsafe, they're less likely to participate in community activities and socially interact with others. Safety is therefore closely related to the previously mentioned socio-cultural characteristics; in a safe community, feelings of trust and cooperation are arguably enhanced, which in turn strengthens social networks and the sense of place.

\subsection{Preferred Convenient Practices}

This aspect relates to people's preferences and habits, such as living in low density suburban houses, or the use of the private car as well as specific shopping or leisure trends. It can be construed that preferred practices and habits are likely to conflict with imposed forces of change, such as the sustainability imperative itself. Vallance (2011) state that many eco-friendly proposals and programmes actually disrupt established patterns of behaviour, values and traditions that people would like to maintain, such as the use of private cars. People may therefore resist making changes that they perceive as a deviation from the ways of living they have built and 
embraced over the years. This argument is supported by Assefa and Frostell (2007), who discuss the undesirable environmental effects that may emerge when sustainability policies are not socially accepted.

Clark (2005) depicts a case where inner city parking fees were designed to encourage the use of public transport. Instead of decreasing private auto-mobility, an 'unanticipated coping strategy' arose, where people simply preferred to drive to suburban malls with free car-parking. Clark then states that the consequences of such strategies may be worse than the original problem. It is thus crucial to understand the reasons behind people's opposing responses if environmental sustainability is to be achieved, otherwise the pursuit of environmental goals may become counter-productive (Vallance, 2011).

\section{A Case Study of El-Raml Station}

Alexandria is the second largest city in Egypt, extending about $32 \mathrm{~km}$ along the coast of the Mediterranean Sea. It has always been a cosmopolitan city, embracing various cultures such as Greek, Roman and Islamic. El-Raml Station is a district in Alexandria, known as one of the primary centres for retail, tourism and entertainment in the city. The area is marked by its famous tram station, and the large public square (Saad Zaghloul Square). It is also known for its strong authentic character and historical value. This part of the city has been designed by a number of Italian architects during the period of 1890 to 1950's as the centre of the old city. One of its defining features is the consistent presence of vendors along the streets, which attracts shoppers and tourists. Several hotels, restaurants and venues for performing arts are also located in the commercial streets shaping the area. With the sprout of population density, and the social changes in the city of Alexandria over the years; the area has witnessed a number of changes that altered the way it functions, as well as the experience of its visitors, as shown in Figures 2 and 3. Changes include higher rates of traffic congestion, and the emergence of modernised indoor shopping malls.

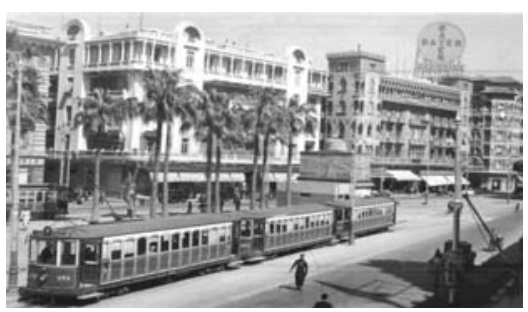

Figure 2: The way El-Raml Station was designed and envisaged originally, is shown in a picture of the area taken in 1940 (Source: Eissa et al, 2011)

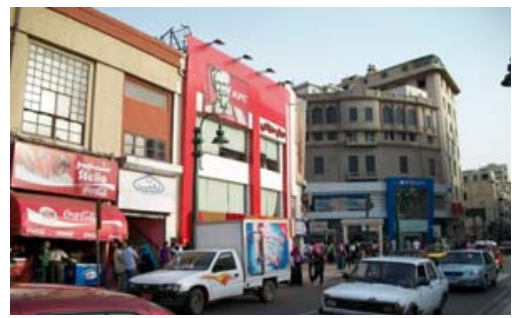

Figure 3: The modernisation of El-Raml Station area as shown in a picture taken in 2012 (Source: Google Images)

It is thus significant to assess the maintenance of socio-cultural characteristics in such a dynamic area of the city, and how people perceive them. It is difficult to define the actual number of 
visitors in the area, yet they are estimated to be around 500,000 a week. Based on this and on a confidence level of $95 \%$; the sample size for the questionnaires was decided to be 300 people. Sample selection was systematically random; every third person passing by was asked to fill in the questionnaire. Approximately $10 \%$ refused to fill in the questionnaire, displaying unease and discomfort, constraining the study. Others were reluctant and suspicious, yet the overall majority was happy to help. In order to minimize validity issues and gain a good representation of people's perceptions, the selection took place over the course of one week, including weekends, at different times of the day.

The adopted approach regarding the scheduled interviews was deliberately selective, where it was ensured that different economic and social categories were covered in both genders. 25 scheduled interviews were conducted over the course of one week. They provided a clearer, more intimate insight of people's established perceptions.

\subsection{Results}

\subsubsection{Questionnaire Results}

People visit El-Raml Station for different purposes. Figure 4 indicates that the most common reasons for visiting El-Raml Station are shopping and meeting friends (approximately $30 \%$ each), whilst walking and leisure fall just below $20 \%$.

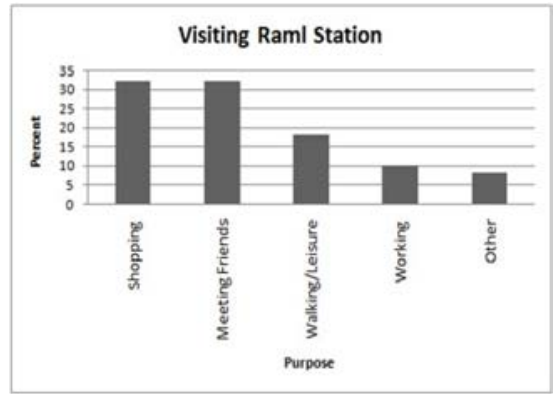

Figure 4: Reasons for visiting El-Raml Station.

About 50\% of people aged from 21-30 rated El-Raml Station as a good place to socialize, compared with about $10 \%$ claiming it was poor. On the other hand, more than $50 \%$ of people aged from 51-60 stated that it was a poor place for socializing, compared with roughly $15 \%$ rating it as good (Figure 5).

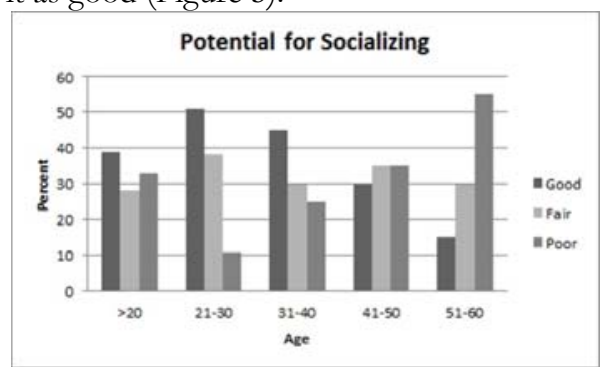

Figure 5: Different age-group ratings of El-Raml Station as a place suitable for socializing.

The majority of people asked agree that El-Raml Station has a pleasant, powerful cultural character (nearly 70\%), and only 6\% state the opposite, as shown in Figure 6. 


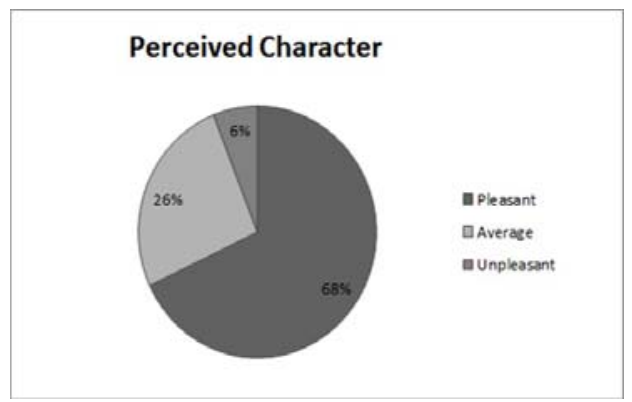

When people were asked whether or not they have pleasant memories relating to El-Raml Station, nearly three quarters of them mentioned that the place does in fact evoke pleasant memories and emotions (Figure 7).

Figure 6: Evaluation of El Raml Station's perceived cultural character.

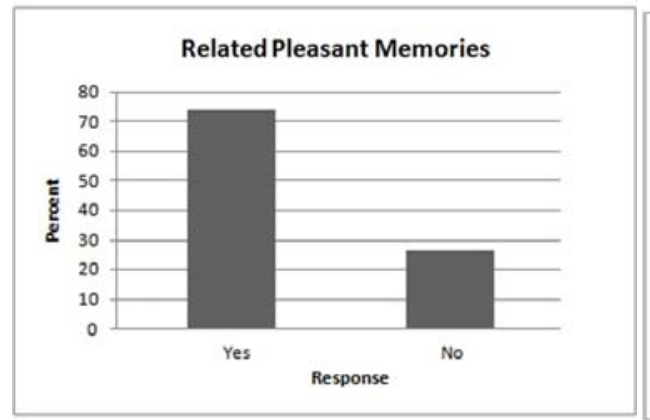

Figure 7: Responses regarding having pleasant memories associated with El Raml Station.

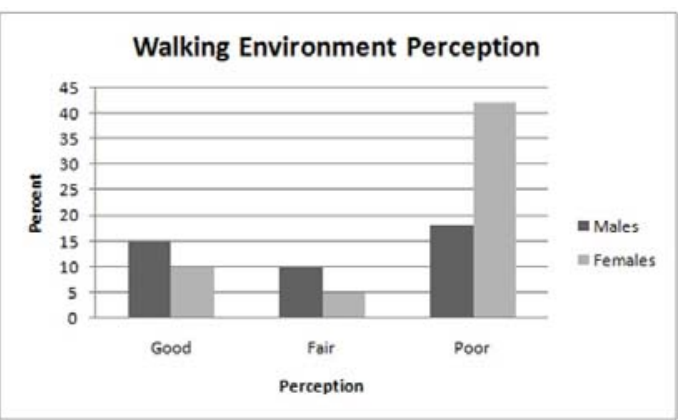

Figure 8:Evaluation of El Raml Station's perceived walking environment of males and females.

Regarding the perceived walking environment, almost $60 \%$ stated that walking conditions are poor and nearly $70 \%$ of those were females. $25 \%$ stated that walking conditions are good, and out of those nearly $60 \%$ were males (Figure 8 ).

Figure 9 demonstrates that nearly $65 \%$ of people whose income is below the minimum wage of 1200 Egyptian pounds claim that shopping facilities in El-Raml Station are good, and less that $10 \%$ state that they are poor. On the contrary, approximately $70 \%$ of those whose income is above 7000 pounds rate shopping facilities as poor, with a minority of $5 \%$ stating the opposite.

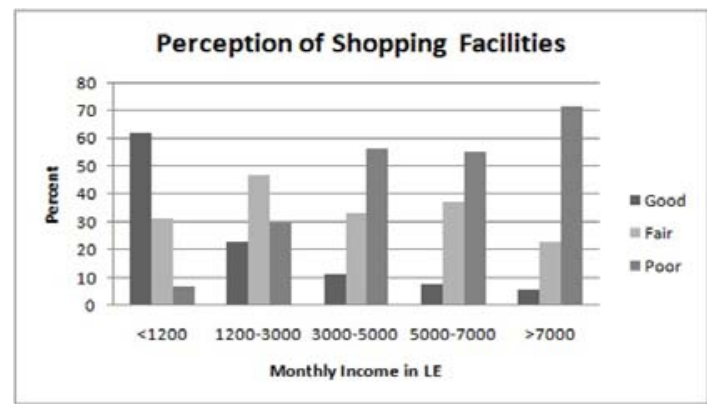

Figure 9:Different income groups ratings of El-Raml Station's shopping facilities.

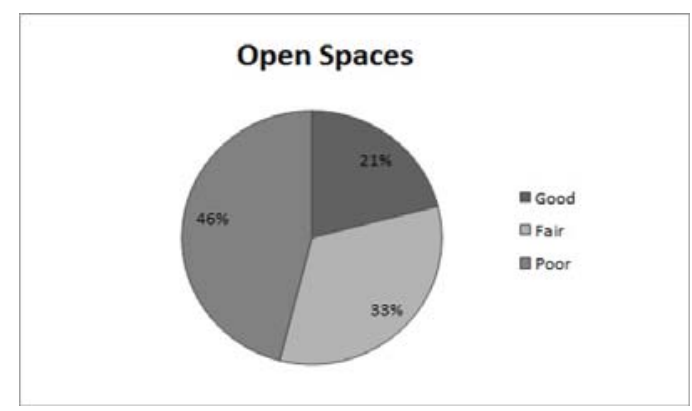

Figure 10:Evaluation of available open spaces assigned for leisure.

When the selected sample was asked to rate the quality of public open spaces assigned for leisure, the results reveal that almost 50\% stated that open spaces in El-Raml Station are poor, whilst only 
about $20 \%$ stated that they were satisfactory, as seen in Figure 10.

\subsubsection{Interviews Results}

Scheduled interviews were very useful in providing a personal, in-depth understanding of the public's perception of El-Raml Station. Below are three chosen samples:

Interviewee 1 was a 42 year old married man, working as a security guard in a sports club. He passes by El-Raml Station everyday on his way to work. When asked about what he would like to improve/change in the area, his response was the following:

Interviewee 1: "I used be able to take my family out on weekends in El-Raml Station; the streets were not crowded, the open spaces were clean, and the people were decent. Now I no longer take my family with me- I just go alone, buy them what they need and then return home. I don't feel it is safe for my wife and children anymore because the people's attitudes have changed and the streets are always congested."

Interviewee 2 was a 52 year old single mother, working as a housemaid. She goes shopping in ElRaml Station every now and then and her son usually accompanies her.

Interviewee 2: "This place is so beautiful, though they recently started building ugly 15-storey residential buildings and ruining the area's character. I just wish they would stop and preserve what is left of the old buildings. I would also appreciate it if street vendors were located somewhere else, so we can walk on the pavements without stacks of goods obstructing our way" Interviewee 3 was a 27 year old young man, working at an electronics store. He visits El-Raml Station on weekends to meet his friends for a couple of hours.

Interviewee 3: "Cinemas and shops have not changed for years. The whole world is moving forward, and places are continuously developing to suit future needs, but here we are just standing still. I think shopping facilities and recreational area should be developed to prevent El-Raml Station from seeming somehow outdated."

It was noted that more than half of the interviewees expressed the need for more high-quality public open spaces, stating that more greenery and seating would be appreciated and would generate a more fit centre of Alexandria. They also demanded the preservation of the cultural and architectural character of the area along with restoring any structures that require maintenance.

The majority of the mid-aged interviewees mentioned that walking conditions desperately need to be improved, pavements need to be maintained, and street vendors need to be located elsewhere. They emphasized that all of these factors are restricting their activities in El-Raml Station, as well as reducing their enjoyment and comfort. However, most of the relatively younger interviewees awarded the development of commercial areas like cinemas and retail shops more importance than improving the walking environment. Women in particular tended to complain about the disappointing amounts of garbage on the streets, whereas men mainly complained about the highly congested walkways and streets.

\subsection{Discussion}

The extent to which socio-cultural characteristics are maintained in El-Raml Station can be evaluated based on the obtained results and their implications. As deduced from the studies in section 4, the maintenance of socio-cultural characteristics involves four aspects, the first one being 'social cohesion'. One might assume that since 'meeting friends' appears to be one of the most common reasons for visiting El-Raml Station, that the area is considered suitable for socializing for all groups of people. To make this assumption would be inaccurate. The results point out a striking variation between different age-group ratings of El-Raml Station as a place suitable for socializing, indicating that it is possibly more equipped for youth socialization, resulting in the mid-aged and elderly feeling somehow inferior. This may be due to the scarcity of facilities demanded by the elderly, or that the pace, noise and crowds are perceived as too high for their 
preferred socializing conditions. One of the important implications of social cohesion is the elimination of forms of polarization of any group of people, as discussed in the literature investigation. Therefore, the apparent result that the youth feel more invited to socialize than other age groups may in fact compromise social cohesion.

The second aspect concerns 'sense of place' and 'cultural character'. Obtained results not only signify that the place's character is thought of as appealing, but also highlight the importance of preserving it, as it is a desirable socio-cultural characteristic that people want to see maintained. Moreover, the majority of people seem to have pleasant memories related to the place, which offers further confirmatory insight on people's perception of El-Raml Station's cultural character. 'Territorial belonging', as mentioned in the literature review, can be considered an attribute of social cohesion, and thus the apparent presence of a strong sense of place may have positive spill-over effects, most likely enhancing social cohesion.

'Safety' is the third studied aspect. Assessing the perceived safety of El-Raml Station entailed the evaluation of the walking environment primarily. Having a relatively poor walking environment, as the above results denote, means that safety is most likely jeopardized, which in turn adversely affects the potential to socialize and people's sense of attachment to the place. As interview results suggest, people's attitudes along with the excessive prevalence of street vendors have reduced the area's sense of safety and comfort. It is also noticeable that females have worse perceptions on the walking environment than males, suggesting that they go through a fairly less safe and less pleasing walking experience. This may be due to the nature of the local society, in terms of congestion and possibly different forms of harassment (verbal harassment in particular). The final aspect addresses 'preferred convenient practices'. It can be inferred that preferred practices or habits associated with El-Raml station are shopping, meeting friends, walking and leisure (Figure 4); hence the maintenance of these practices is preferable. The results suggest that the preferred habit of shopping in El-Raml Station is only well maintained for lower income groups. Interview results further support this, as the majority of interviewees requested the development of a wider variety of commercial areas. Favoured leisure and socializing opportunities may also be limited due to the perceived poor quality of public open spaces. Congestion more often than not results in chaotic environments, which may be the reason why open spaces are of degraded quality, and why perceived safety is threatened. It can be concluded from people's established perceptions that their preferred convenient practices are somehow restricted- either by under-developed shopping facilities, insufficient high quality public open spaces or poor walking conditions.

\section{Conclusions}

This paper covers a range of social sustainability aspects suggested by numerous theorists. Particular focus is directed towards the 'maintenance of socio-cultural characteristics' and a framework of four testable criteria is drawn up to address the practicality of this aspect rather than merely identifying its conceptual attributes.

Assessing the 'maintenance of socio-cultural characteristics' in El-Raml Station reveals that all aspects are in fact strongly interrelated. The preservation of El-Raml's cultural character is likely to strengthen the area's sense of place, which in turn should enhance social cohesion. Poor walking conditions limit people's preferred practices, threaten perceived safety, and may consequently compromise social cohesion. This calls planning authorities to consider all aspects of socio-cultural characteristics in a comprehensive plan as opposed to focusing on developing one at a time.

There is undoubtedly a need for more rigorous research addressing the challenges of the possible conflicts between social sustainability aspects and their operational translation in the material fabric of cities. Whether other factors such as ethnic background or the local nature of a society affect the perception of an area's socio-cultural characteristics merits further investigation. 
Thorough understanding of the term's practical applications can possibly guide future planning decisions in order to achieve more sustainable communities.

\section{Acknowledgements}

I would like to thank the staff at the Library of Alexandria for their generous guidance and provision of helpful sources.

\section{References}

Assefa, G. F. (2007). Social sustainability and social acceptance in technology assessment: a case study of energy technologies. Technology in Society 29 , 63-78.

Bacon, N. (2012). Social sustainability and new communities: moving from concept to practice in the UK. Future Communities: Socio- cultural and Environmental Challenges (pp. 29-42). Giza: The Berkeley Group.

Barton, H. (2000). Conflicting perceptions of neigbbourbood. In Sustainable Communities: the Potential for EcoNeighbourhoods,. London: Earthscan.

Berkman, L. K. (2000). Social Epidemiology. Oxford: Oxford University Press.

Campbell, S., Green cities, growing cities, just cities? Urban planning and the contradictions of sustainable development1996 Journal of the American Planning 62 296-312

Chiu, R. (2003). Social sustainability and sustainable housing. Housing and Social Change, 221- 239.

Clark, M. (2005). The compact city: European ideal, global fix or myth? Global Built Environment Review 4 (3), $1-11$.

Eissa, I. A.-H. (2011). blackwhite. Retrieved December 27, 2014, from http://www.tnnegypt.com/: http://www.tnnegypt.com/blackwhite/

El-Husseiny, M., Kesseiba, K.. (2012). Challenges of social sustainability in neo-liberal Cairo: requestioning the role of public space. Social and Behavioral Sciences $68,790-803$.

Fischer, C. (1982). To Dwell among Friends. Chicago: University of Chicago Press.

Foladori, G. (2005). Advances and limits of social sustainability as an evolving concept. Canadian Journal of Development Studies 26(3), 501- 510.

Godschalk, D., Land use planning challenges: coping with conflicts in visions of sustainable development and livable communities 2004Journal of the American 70(1) 5- 13

Google Images. (n.d.). Retrieved March 28, 2015, from www.google.com: http://eg.worldmapz.com/photo/31527_en.ht m

Holden, M. (2012). Urban Policy Engagement with Social Sustainability in Metro Vancouver. Urban Studies, 527-542.

Keams, A. F. (2000). Social cohesion and multilevel urban governance. Urban Studies, 37(5/6), 995-1017.

Knox, P. (2011). Cities and Design. New York: Routledge.

Landorf, C., Evaluating social sustainability in historic urban environments2011International Journal of Heritage Studies (17) 463- 477

Lynch, K. (1960). The Image of the City. Cambridge, Massachusetts, and London, England: MIT Press.

Maslow, A. (1954). Motivation and Personality. New York: Harper.

Polese, M. and Stren,R.2000The Social Sustainability of Cities: Diversity and the Management of ChangéTorontoUniversity of Toronto Press

Putnam, R. (1993). Making Democracy Work: Civic Traditions in Modern Italy. Princeton: Princeton University Press.

Relph, E. (1976). Place and Placelessness. London: Pion.

Sachs, I. (1999). Social Sustainability and Whole Development. New York: Zed Books, UNESCO.

Talen, E. (1999). Sense of community and neighbourhood form: an assessment of the social doctrine of new urbanism. Urban Studies, 36, 1361- 1379.

Vallance, S. P. (2011). What is social sustainability? A clarification of concepts. Geoforum, 42 , 248- 342. 